\title{
ВИКОРИСТАННЯ МЕТОДУ ЛОГІЧНИХ ІГОР ПРИ ВИКЛАДАННІ НЕВІДКЛАДНИХ СТАНІВ У СТРУКТУРІ ДИСЦИПЛІНИ “СІМЕЙНА МЕДИЦИНА”
}

\author{
O. O. Khaniukov, O. V. Smolyanova \\ Dnipropetrovsk Medical Academy, Dnipro
TEACHING EMERGENCY CARE THROUGH USING LOGIC GAMES METHOD IN THE STRUCTURE OF THE DISCIPLINE OF FAMILY MEDICINE

\begin{abstract}
Мета роботи - оцінити ефективність використання методу логічних ігор як самостійної роботи студентів під час вивчення дисципліни “Сімейна медицина”.

Основна частина. У дослідженні було використано метод логічних ігор (кросворд) для підготовки до теми “Організація надання невідкладної допомоги в практиці сімейного лікаря. Невідкладна допомога, що надається сімейним лікарем у випадку раптової смерті на догоспітальному етапі” у студентів 6 курсу, що вивчали дисципліну “Сімейна медицина”. У дослідженні взяли участь 56 студентів, які були розподілені на 2 групи: перша (25 студентів) готувалася до заняття, використовуючи лише методичні рекомендації, друга (31 студент) - на додаток до методичних рекомендацій отримала кросворд, складений співробітниками кафедри, який містив 0 питань 3 відповідної теми. Кросворд було видано за 1 день до теми з метою спрямувати увагу студента на важливі деталі під час підготовки до заняття: етіологію, препарати та їх дозування, особливості ЕКГ. На занятті було роздано кейси за темою з питаннями без запропонованих можливих відповідей. Отримані результати виявили збільшення успішності студентів другої групи порівняно зі студентами першої.

Висновки. Використання методу логічних ігор допомагає, з одного боку, підвищити активну складову навчання та додати позитивних емоцій у навчальний процес. Це, у свою чергу, сприяє кращому засвоєнню отриманих знань. 3 іншого боку, дана методика сприяє спрямуванню уваги на запам’ятовування важливих у діяльності лікаря термінів і назв лікарських засобів з точним дозуванням.
\end{abstract}

Ключові слова: кросворд; студенти; сімейна медицина; невідкладні стани; інноваційні методи навчання.

The aim of the work - to evaluate the efficacy of using logic games method as the students' independent work during the study of the discipline of Family Medicine.

The main body. A logic game method (crossword puzzle) was used in the research to prepare for the topic "Organization of emergency care in the practice of a family doctor. Emergency aid that to be provided by the family doctor in case of sudden death at a prehospital stage" in the 6th year students who studied the subject "Family medicine". 56 students participated in the research were divided into 2 groups: the group 1 (25 students) was preparing for the class, using only methodological recommendations, the group 2 (31 students) in addition to the methodological recommendations received a crossword with 30 questions on the relevant topic composed by the staff of the department. The crossword puzzle was given 1 day prior to the topic in order to direct the students attention to important details during the preparation for the lesson, e.g. etiology, drugs and their dosage, features of the ECG. At the lesson, "cases” on the topic with questions without the suggested possible answers were given to both groups. The obtained results revealed an increase in the progress of the students of the group 2 in comparison with the students of the group 1.

Conclusions. On the one hand, the use of logic games method helps to increase the active component of learning and add positive emotions to the learning process. This, in turn, promotes a better assimilation of the gained knowledge. On the other hand, this technique helps to focus attention to remember the terms and drug names with accurate dosages, which is important in the doctor practice.

Key words: crossword puzzles; students; family medicine; emergency care; innovative teaching methods.

Вступ. Компетентність лікаря зумовлює його професійність. Відповідно до освітньої програми за спеціальністю “Лікувальна справа”, одними 3 фахових компетентностей, якими повинен оволо-

(C) О. О. Ханюков, О. В. Смольянова діти студент-медик, є здатність до діагностування, визначення тактики та надання екстреної допомоги при невідкладних станах. Особливо гостро ця проблема виникає у практиці лікаря загальної практики - сімейного лікаря, значущим розділом 
діяльності якого є робота з пацієнтами за межами лікувального закладу. У таких умовах лікар може покладатися лише на свої знання, уміння та навички.

Мета роботи - оцінити ефективність використання методу логічних ігор як самостійної роботи студентів під час вивчення дисципліни “Сімейна медицина”.

Основна частина. Високий рівень знань залежить від вмотивованості студента під час підготовки до занять. 3 одного боку, на рівень вмотивованості впливає емоційна складова. Психологічний комфорт під час навчання - це важливий предиктор подальшого прагнення до вивчення предмета [1, 2]. 3 іншого боку, доведено, що студенти досягають кращих результатів, коли беруть активну участь у набутті знань. Автономна мотивація асоціюється з кращим навчанням, академічним успіхом та меншим виснаженням [3-8].

Використання різних ігор на заняттях - це бажаний навчальний метод, який може перетворити навчання в менш “загрозливий” та більш приємний процес однаково як для студентів, так і для викладачів, а також додати до нього активну складову $[9,10]$. Одним із таких методів є кросворд, перевагами якого $є$ те, що студенти відіграють активну роль у прийнятті рішень і розв'язанні проблем, а також реагують на результати їх власних рішень [11]. Цілями використання кросворду на заняттях можуть бути такі: заохочення до активного читання літератури під час підготовки до заняття (практика активної роботи з літературою); навчання важливості самодисципліни у розвитку гарних навчальних звичок; отримання нового словникового запасу (термінології); проведення диференціації між схожими словами; правильне написання термінів $[11,12]$. Крім того, кросворд заохочує дедуктивне обгрунтування та критичне мислення більше, ніж пасивне запам’ятовування матеріалу, посилює впевненість та здатність до навчання [13, 14]. Він особливо ефективний у вивченні деталей, які необхідно запам'ятати, як, наприклад, назва та дозування лікарських засобів, показання тощо. Це ефективний інструмент як для викладання, так і для організації самостійної роботи студентів $[15,16]$.

Зважаючи на вищеперераховане, ми використали кросворд для підготовки до теми “Організація

\section{Список літератури}

1. Medical students' motivation for internal medicine / G. C. Williams, M. W. Wiener, K. M. Markakis [et al.] // Journal of General Internal Medicine. - 1994. - Vol. 9, No. 6. - P. 327-333. надання невідкладної допомоги в практиці сімейного лікаря. Невідкладна допомога, що надається сімейним лікарем у випадку раптової смерті на догоспітальному етапі” у студентів 6 курсу спеціальностей “Лікувальна справа”, “Педіатрія”, що вивчали дисципліну “Сімейна медицина” в 11 семестрі. У дослідженні взяли участь 56 студентів, які були розподілені на 2 групи: перша (25 студентів) готувалася до заняття, використовуючи лише методичні рекомендації, друга (31 студент) - на додаток до методичних рекомендацій отримала кросворд, складений співробітниками кафедри, який містив 30 питань з відповідної теми. Кросворд було видано за 1 день до теми з метою спрямувати увагу студента на важливі деталі під час підготовки до заняття: етіологію, препарати та їх дозування, особливості ЕКГ. На занятті було роздано кейси за темою з питаннями без запропонованих можливих відповідей.

При порівнянні результатів виявлено, що при призначенні лікування правильний препарат було обрано у 67 \% випадків студентами першої групи та 91 \% - другої, у той час як правильне дозування було вказано у 53 \% та 81 \% випадків студентами першої та другої груп відповідно. При розшифровуванні ЕКГ студенти з другої групи частіше використовували коректні терміни (87 \% випадків) порівняно зі студентами першої групи (65 \% випадків). Тобто успішність студентів з основної групи була вищою порівняно з контрольною групою.

При опитуванні після заняття студенти другої групи позитивно оцінили методику використання кросворду при підготовці до заняття, та висловили побажання отримувати кросворд для самопідготовки і за іншими темами.

Висновки. Використання кросвордів допомагає, з одного боку, підвищити активну складову навчання та додати позитивних емоцій у навчальний процес. Це, у свою чергу, сприяє кращому засвоєнню отриманих знань. 3 іншого боку, дана методика сприяє акцентуванню уваги на запам'ятовування важливих у діяльності лікаря термінів і назв лікарських засобів з точним дозуванням. Дана методика самопідготовки до занять була позитивно оцінена студентами, та сприяла покращенню успішності студентів.

2. Uzezi J. G. Effectiveness of brain-based learning strategy on students' academic achievement, attitude, motivation and knowledge retention in electrochemistry / J. G. Uzezi, K. J. Jonah // Journal of Education, Society and Behavioural Science. - 2017. - Vol. 21, No. 3. - P. 1-13. 
3. Kusurkar R. A. Autonomy support for autonomous motivation in medical education / R. A. Kusurkar, G. Croiset // Medical Education Online. - 2015. - Vol. 20. - P. 27951.

4. Martínez M. I. Active learning: creating interactive crossword puzzles / M. I. Martínez, J. F. Parra // EDULEARN11 Proceedings. - 2011. - P. 5030-5034.

5. Agarwal A. Creative pathology teaching with word puzzles until students learn: a study in a medical university / A. Agarwal, S. A. M. Rao // Asian Journal of Research in Medical and Pharmaceutical Sciences. - 2017. - Vol. 2, No. 3. - P. 1-7.

6. Shah S. Crossword puzzles as a tool to enhance learning about anti-ulcer agents / S. Shah, L. M. J. Lynch, L. Z. Macias-Moriarity // American Journal of Pharmaceutical Education. - 2010. - Vol. 74, No. 7. - P. 117-121.

7. Gaikwad N. Crossword puzzles: self-learning tool in pharmacology / N. Gaikwad, S. Tankhiwale // Perspectives on Medical Education. - 2012. - Vol. 1, No. 5-6. P. 237-248.

8. Bailey C. M. Educational puzzles for understanding gastrointestinal physiology. / C. M. Bailey, C. T. Hsu, S. E. DiCarlo // Advances in Physiology Education. 1999. - Vol. 276, No. 6. - P. S1-S18.

9. Weisskirch R. S. An analysis of instructor-created crossword puzzles for student review / R. S. Weisskirch // College Teaching. - 2006. - Vol. 54, No. 1. - P. 198-202.

\section{References}

1. Williams, G.C., Wiener, M.W., Markakis, K.M., Reeve, J., \& Deci, E.L. (1994). Medical students' motivation for internal medicine. Journal of General Internal Medicine, 9 (6), 327-333.

2. Uzezi, J.G., \& Jonah, K.J. (2017). Effectiveness of brain-based learning strategy on students' academic achievement, attitude, motivation and knowledge retention in electrochemistry. Journal of Education, Society and Behavioural Science, 21 (3), 1-13.

3. Kusurkar, R.A., \& Croiset, G. (2015). Autonomy support for autonomous motivation in medical education. Medical Education Online, 20, 27951. Retrieved from: https://doi.org/10.3402/meo.v20.27951.

4. Martínez, M. I., \& Parra, J. F. (2011). Active learning: creating interactive crossword puzzles. EDULEARN11 Proceedings, 5030-5034.

5. Agarwal, A., \& Rao, S.A.M. (2017). Creative pathology teaching with word puzzles until students learn: A study in a medical university. Asian Journal of Research in Medical and Pharmaceutical Sciences, 2 (3), 1-7.

6. Shah, S., Lynch, L.M.J., \& Macias-Moriarity, L.Z. (2010). Crossword puzzles as a tool to enhance learning about anti-ulcer agents. American Journal of Pharmaceutical Education, 74 (7), 117-121.

7. Gaikwad, N., \& Tankhiwale, S. (2012). Crossword puzzles: self-learning tool in pharmacology. Perspectives
10. Franklin S. Non-traditional interventions to stimulate discussion: the use of games and puzzles / S. Franklin, M. Peat, A. Lewis // Journal of Biological Education. 2003. - Vol. 37, No. 2. - P. 79-84.

11. McKeachie W. J. McKeachie's teaching tips: strategies, research, and theory for college and university teachers / W. J. McKeachie, G. Gibbs. - Boston : D C Heath \& Co, 1999. - 379 p.

12. Gupta S. The puzzle game: a novel approach to teaching accounting / S. Gupta, R. J. Elson, S. A. Ostapski // The Accounting Instructors' Report. - 2006. - P. 1-5.

13. Jaramillo C. M. Z. Designing and solving crossword puzzles: examining efficacy in a classroom exercise / C. M. Z. Jaramillo, B. M. Losada, M. J. Fekula // Developments in Business Simulation and Experiential Learning: Proceedings of the Annual ABSEL conference. - 2012. Vol. 39, No. 1. - P. 213-222.

14. The usefulness of crossword puzzle as a self-learning tool in pharmacology / S. Patrick, K. Vishwakarma, V. C. Giri [et al.] // Journal of Advances in Medical Education \& Professionalism. - 2018. - Vol. 6, No. 4. - P. 181-185.

15. Speers A. T. Crossword puzzles: a teaching strategy for critical care nursing / A. T. Speers // Dimensions of critical care nursing: DCCN. - 1994. - Vol. 13, No. 1. - P. 52-55.

16. Jhaveri K. D. Nephrology crossword: glomerulonephritis / K. D. Jhaveri // Kidney International. - 2010. Vol. 77, No. 12. - P. 1141-1142.

on Medical Education, 1(5-6), 237-248. https://doi. org/10.1007/s40037-012-0033-0.

8. Bailey, C.M., Hsu, C.T., \& DiCarlo, S.E. (1999). Educational puzzles for understanding gastrointestinal physiology. Advances in Physiology Education, 276 (6), S1-S18. https://doi.org/10.1152/advances.1999.276.6.S1.

9. Weisskirch, R.S. (2006). An analysis of instructorcreated crossword puzzles for student review. College Teaching, 54 (1), 198-202.

10. Franklin, S., Peat, M., \& Lewis, A. (2003). Nontraditional interventions to stimulate discussion: the use of games and puzzles. Journal of Biological Education, 37 (2), 79-84. https://doi.org/10.1080/00219266.2003.9655856.

11. McKeachie, W.J., \& Gibbs, G. (1999). McKeachie's Teaching Tips: Strategies, Research, and Theory for College and University Teachers (10th edition). Boston: D C Heath \& Co.

12. Gupta, S., Elson, R., \& Ostapski, S.A. (2006). The puzzle game: A novel approach to teaching accounting, The Accounting Instructors' Report, 1-5.

13. Jaramillo, C.M.Z., Losada, B.M., \& Fekula, M.J. (2012). Designing and solving crossword puzzles: Examining efficacy in a classroom exercise. Developments in Business Simulation and Experiential Learning: Proceedings of the Annual ABSEL Conference, 39 (0), 213-222. 
14. Patrick, S., Vishwakarma, K., Giri, V. P., Datta, D., Kumawat, P., Singh, P., \& Matreja, P.S. (2018). The usefulness of crossword puzzle as a self-learning tool in pharmacology. Journal of Advances in Medical Education \& Professionalism, 6 (4), 181-185.
15. Speers, A.T. (1994). Crossword puzzles: a teaching strategy for critical care nursing. Dimensions of Critical Care Nursing: DCCN, 13 (1), 52-55.

16. Jhaveri, K.D. (2010). Nephrology crossword: glomerulonephritis. Kidney International, 77 (12), 11411142. https://doi.org/10.1038/ki.2010.59.

Електронна адреса для листування: smolyanova@ukr.net 